\title{
PROPAGAÇÃO DO MARACUJAZEIRO EM DIFERENTES SUBSTRATOS
}

Lasara Kamila Ferreira de Souza ${ }^{1}$, Karminne Dias Do Valle ${ }^{2}$, Moab Acácio Barbosa ${ }^{3}$, Diego Ismael Rocha ${ }^{4}$ \& Danielle Fabíola Pereira da Silva ${ }^{5}$

1 - Engenheira florestal, mestranda em Agronomia (Bolsista da CAPES), Universidade Federal de Jataí, Jataí-GO, engekah.lk@gmail.com

2 - Discente do Curso de Agronomia (Bolsista do CNPq), Universidade Federal Jataí, Jataí-GO, Brasil, karminnevalle@gmail.com

3 - Discente do Curso de Agronomia, Universidade Federal de Jataí, Jataí-GO, moabacacio@gmail.com

4 - Engenheiro agrônomo, professor, Universidade Federal de Jataí, Jataí-GO, diegoirocha@gmail.com

5 - Engenheira agrônoma, professora, Universidade Federal de Jataí, Jataí-GO, daniellefpsilva@gmail.com

\section{Palavras-chave:}

crescimento

formação de mudas

Passiflora edulis f. flavicarpa

\section{RESUMO}

A obtenção de mudas de qualidade é resultante da utilização de substratos uniformes e estáveis, que garantem a eficiência do crescimento e desenvolvimento das plantas. No presente estudo, foi avaliada a propagação do maracujazeiro-azedo (Passiflora edulis f. flavicarpa) e da cultivar FB 200 (Flora Brasil). O experimento foi conduzido no viveiro da Universidade Federal de Jataí. Os tratamentos foram constituídos por: substrato comercial (Bioplant $\left.{ }^{\circledR}\right)(\mathrm{S} 1)$, solo contendo 2 partes de solo +1 parte de esterco +1 parte de areia (S2) e solo proveniente de barranco, corrigido segundo a necessidade da cultura (S3). O delineamento experimental foi inteiramente casualizado em esquema de parcela subdivida no tempo, tendo nas parcelas os três substratos e nas subparcelas as épocas de avaliação com oito repetições e quatro mudas por unidade experimental. Os parâmetros avaliados aos 30, 35, 40, 45, 50, 55 e 60 dias após a semeadura (DAS) foram: graus-dia, massa fresca e seca da planta, massa fresca e seca da parte aérea, massa fresca e seca da raiz, número de folhas, área foliar, área foliar específica, taxa de crescimento absoluto, diâmetro do caule e teor de clorofila total. Com base nas características avaliadas, concluiu-se que o substrato comercial Bioplant ${ }^{\circledR}$ proporcionou a obtenção de mudas de melhor qualidade.

\section{Keywords:}

growth

seedling formation

Passiflora edulis f. flavicarpa

\section{PROPAGATION OF PASSION FRUIT ON DIFFERENT SUBSTRATES}

\section{ABSTRACT}

The obtention of quality seedlings results from using uniform and stable substrates in order to guarantee growth efficiency and development of the plants. In the present study, the propagation of sour passion fruit (Passiflora edulis f. flavicarpa) and cultivar FB 200 (Flora Brasil) were evaluated using commercial substrate and two types of soils. The experiment was carried out in the nursery of the Federal University of Jataí. Treatments were composed of: commercial substrate $\left(\right.$ Bioplant $\left.^{\mathbb{R}}\right)(\mathrm{S} 1)$, soil containing 2 parts of soil +1 part of manure +1 part of sand (S2) and soil from ravine, corrected according to the need of the crop (S3). The experimental design was the completely randomized plot subdivided in time, having the three substrates in the plots, and the evaluation times with eight replicates and four seedlings per experimental unit in the subplots. The parameters evaluated at 30, 35, 40, 45, 50, 55 and 60 days after sowing (DAS) were: Degrees/Day, fresh and dry plant mass, fresh and dry shoot mass, fresh and dry roots mass, number of leaves, leaf area, specific leaf area, absolute growth rate, stem diameter and total chlorophyll content. Based on all the characteristics evaluated, it was concluded that the commercial substrate Bioplant ${ }^{\mathbb{B}}$ provided the best quality seedlings. 


\section{INTRODUÇÃO}

A importância da cultura do maracujazeiro é crescente em nível mundial. No Brasil, um dos maiores produtores de maracujá, a cultura encontrase em grande expansão devido às demandas dos mercados alimentícios e cosméticos. No ano de 2016, foi produzido um total de 703.489 toneladas, em uma área colhida de 49.889 hectares (IBGE, 2018).

O cultivo em sua maior totalidade ocorre com a utilização da espécie maracujazeiro-azedo ou amarelo, que, segundo Damatto-Júnior et al.(2014), representa $97 \%$ das áreas destinadas ao plantio. O seu estabelecimento ocorre em pequenas e médias propriedades, potencializando os investimentos em fruticultura, sendo, por isso, de grande importância econômica e social (MOREIRA et al., 2015).

Um dos meios de se elevar a produtividade nos pomares e obter a precocidade na primeira colheita é o plantio de mudas de qualidade, homogêneas e que possuam condições de serem produzidas de forma mais rápida com baixo custo (REIS et al., 2014). De acordo com Silva et al. (2001), as mudas são o principal insumo na implantação de pomares que, se bem manejados, geram grande rentabilidade.

O sucesso da obtenção de mudas de qualidade está relacionado com vários fatores, dentre eles pode se destacar o tipo de substrato utilizado (VALLE et al., 2018a). Segundo Nogueira et al. (2014), variações na composição dos substratos podem influenciar diretamente a germinação e o estabelecimento das plântulas. Um substrato de qualidade deve estar livre de patógenos e conter $\mathrm{pH}$ ideal, além de possuir os nutrientes essenciais ao bom desenvolvimento da planta (GONÇALVES et al., 2014 \& GONDIM et al., 2015).

Ainda para a obtenção de mudas vigorosas, é necessário contar com boas condições fitossanitárias (VALLE et al, 2018a). Vários resíduos orgânicos têm sido utilizados como alternativa para produção de mudas, sendo observados aqueles que apresentam menor custo final e promovam ganhos significativos em termos de crescimento e desenvolvimento das plantas (SILVA SÁ et al., 2017). Dessa forma, objetivou-se com este trabalho avaliar a influência dos substratos no desenvolvimento de mudas do maracujazeiro-azedo e da cultivar FB 200 (Flora Brasil) propagados por sementes.

\section{MATERIAL E MÉTODOS}

O experimento foi conduzido no viveiro telado com interceptação luminosa (60\%), da Universidade Federal de Jataí. O viveiro experimental está implantado em latitude $17^{\circ} 55^{\prime}$ sul e longitude $51^{\circ} 43^{\text {' }}$ oeste. Segundo a classificação de Köppen, o clima da região é do tipo Aw, megatérmico, com a estação seca definida de maio a setembro, e a chuvosa, de outubro a abril. A temperatura média é $23,3^{\circ} \mathrm{C}$ e a média anual de pluviosidade é de $1541 \mathrm{~mm}$.

Foram utilizadas sementes de maracujazeiroazedo (Passiflora edulis f. flavicarpa) e Passiflora edulis f. flavicarpa cultivar FB 200 (Flora Brasil), retiradas de frutos coletados das matrizes do pomar experimental, selecionando frutos de plantas sadias, livres de pragas e doenças.

Os frutos foram colhidos manualmente com tesoura de poda, usando como critério de colheita a coloração amarela do exocarpo. Depois de colhidos, os frutos foram seccionados transversalmente e a mucilagem com as sementes foram retiradas e submetidas à lavagem com água + cal virgem para a remoção da mucilagem. Posteriormente, as sementes foram acondicionadas em peneiras de polietileno e lavadas em água corrente.

As sementes isoladas foram semeadas em 12 de agosto de 2017, em sacos perfurados com capacidade de 1,5 L, contendo três tipos de substratos (S1, S2 e S3). O substrato comercial Bioplant $^{\mathbb{B}}(\mathrm{S} 1)$, segundo o fabricante, é composto por fibra de coco, casca de "pinus", esterco, serragem, vermiculita, casca de arroz, cinza, gesso agrícola, carbonato de cálcio, magnésio, termofosfato magnesiano (yoorin) e aditivos (fertilizantes). O substrato (S2) foi proveniente da mistura de 2 partes de solo +1 parte de terra +1 parte de areia (2:1:1), cuja mistura possuía pH Cacl2 igual a 5,$3 ; \mathrm{P}$ igual a $21,9 \mathrm{mg} / \mathrm{dm}^{3} ; \mathrm{K}$ igual a 1,10 cmolc $/ \mathrm{dm}^{3}$ e teor de $\mathrm{Mg}$ igual a $0,57 \mathrm{cmolc} / \mathrm{dm}^{3}$, em que não foram realizadas correções na mistura propriamente dita. O substrato (S3) foi composto por solo proveniente de barranco com $\mathrm{pH} \mathrm{Cacl} 2$ igual a 5,$9 ; \mathrm{P}$ igual a $3,0 \mathrm{mg} / \mathrm{dm}^{3} ; \mathrm{K}$ igual a 0,02 cmolc $/ \mathrm{dm}^{3}$ e teor de $\mathrm{Mg}$ igual a $0,14 \mathrm{cmolc} / \mathrm{dm}^{3}$, que foi corrigido de acordo com as necessidades da cultura. Foram semeadas três sementes por saco. Depois da germinação, que ocorreu 15 dias após a semeadura (DAS), as mudas foram desbastadas, deixando apenas a plântula mais vigorosa.

Aos $30,35,40,45,50,55$ e 60 dias após a emergência, os efeitos dos tratamentos foram analisados pela avaliação das características: acúmulo de graus-dia (GDa); matéria fresca da planta (MFP), matéria fresca da parte aérea 


\section{PROPAGAÇÃO DO MARACUJAZEIRO EM DIFERENTES SUBSTRATOS}

(MFPA); matéria fresca da raiz (MFR); matéria seca da planta (MSP); matéria seca da parte aérea (MSPA); matéria seca da raiz (MSR); número de folhas (NF); área foliar (AF); taxa de crescimento absoluto (TCA), diâmetro de caule (DC); e teor de clorofila total (TCT).

Para a caracterização das exigências térmicas, foi calculado o somatório de graus-dias (GDa) desde a germinação até a emissão do quinto par de folhas, considerando a temperatura mínima basal $10^{\circ} \mathrm{C}$ e máxima $36^{\circ} \mathrm{C}$ (SALAZAR et al., 2016).

Os teores de MFP, MFPA e MFR foram avaliados através da retirada dos cotilédones e procedeu-se à pesagem da MFP, onde foram lavadas e pesadas individualmente e avaliadas por gravimetria, em balança eletrônica de precisão de 0,1 g. Subsequentemente, foi feita a separação das partes (raízes e partes aéreas), pesando-as de forma individual. Posteriormente, foram submetidas à secagem em estufa a $70^{\circ} \mathrm{C}$, por $72 \mathrm{~h}$, para obtenção dos dados médios em gramas da MSPA, MFR e MSR, conforme metodologia descrita por Nakagawa (1999).

O NF foi obtido por meio de contagem direta. Para análise da AF, foi usada a metodologia seguida de medição não destrutiva proposta por Morgado et al. (2013), em que foram medidos o comprimento da nervura principal (L) e a largura entre os extremos (A), nas espécies com folhas completas (não lobuladas). Essas medições foram feitas por meio de paquímetro digital de $0,001 \mathrm{~mm}$ de precisão. $\mathrm{O}$ produto de L x A foi a variável independente na equação y $=0.596944 \mathrm{X}-0.000821 \mathrm{X}^{2}+1,49412692 * 10^{-6 *} \mathrm{X}^{3}$ $\left(\mathrm{R}^{2}=0,99\right)$ (CASIERRA-POSADA et al., 2007).

O DC foi obtido com paquímetro digital de $0,001 \mathrm{~mm}$ de precisão na região localizada a 3 $\mathrm{cm}$ acima do colo da planta e os resultados foram expressos em milímetros ( $\mathrm{mm}$ ).

Para determinação do teor de clorofila total (TCT), foram feitas avaliações no terço médio da lâmina foliar. Realizou-se leitura com o clorofilômetro ClorofiLOG, modelo CFL 1030, operado de acordo com as especificações do fabricante (FALKER, 2008). Esse procedimento foi realizado em uma folha no terço médio da planta. O clorofilômetro fornece valores chamados Índice de Clorofila Falker (ICF) proporcionais à absorbância das clorofilas.

O experimento foi conduzido delineamento em inteiramente ao acaso, em esquema de parcela subdivida no tempo, tendo nas parcelas os três substratos compondo os tratamentos, nas subparcelas as épocas de avaliação com oito repetições e quatro mudas por unidade experimental.

Os dados obtidos foram submetidos à análise de variância e quando detectada diferença entre as médias, estas foram submetidas ao teste de Tukey com $5 \%$ de probabilidade. Os cálculos referentes às análises estatísticas foram executados, utilizando-se do software estatístico Statistical Analysis System (SAS, 2002). Para os dados quantitativos, foi utilizada a análise de regressão (GOMES, 2000).

\section{RESULTADOS E DISCUSSÃO}

Estimou-se a necessidade térmica para $o$ desenvolvimento vegetativo do maracujazeiroazedo e cultivar FB 200 (Flora Brasil), representado pela fase de muda (Figura 1). Os acúmulos térmicos serviram para estimar o comportamento da planta diante de variações de temperatura pelas quais passaram durante seus estádios, o qual refletiu diretamente no seu desenvolvimento, permitindo determinar a sua adaptabilidade ao local de implantação (RENATO et al., 2013).

A soma térmica obtida para o maracujazeiroazedo e cultivar FB 200 correspondeu a um fotoperíodo crescente, indo de agosto a setembro com a temperatura oscilando de 23,4 a $29,6^{\circ} \mathrm{C}$, considerada ideal para a cultura, justificando o acúmulo de GDa em um menor tempo de avaliação. As exigências térmicas para o maracujazeiroazedo e cultivar FB 200 foram de 726,7 GDa da germinação até a emissão do quinto par de folhas, sendo necessários 44 dias de acúmulo térmico para o desenvolvimento vegetativo.

Em função do substrato utilizado, as mudas da cultivar FB 200 e do maracujazeiro-azedo demonstraram variações no teor de MFP, melhor desempenho foi verificado para o S1. Procedeu-se ao ajuste exponencial para as mudas da cultivar FB 200 e quadrático para mudas do maracujazeiroazedo (Figura 2A e Figura 2B).

Para variável MSP da cultivar FB 200 e do maracujazeiro-azedo cultivadas no S1, observou-se ajuste quadrático. Aos 30 DAS, as médias de MSP para as mudas da cultivar FB 200 foi de $0,04 \mathrm{~g}$ e 0,86 g MSP para mudas do maracujazeiro-azedo, evidenciado efeito significativo na utilização do substrato comercial por ter favorecido o maior acúmulo de massa seca em toda a planta (Figura 2C e Figura 2D).

De acordo com Marinho et al. (2017), o PSP 


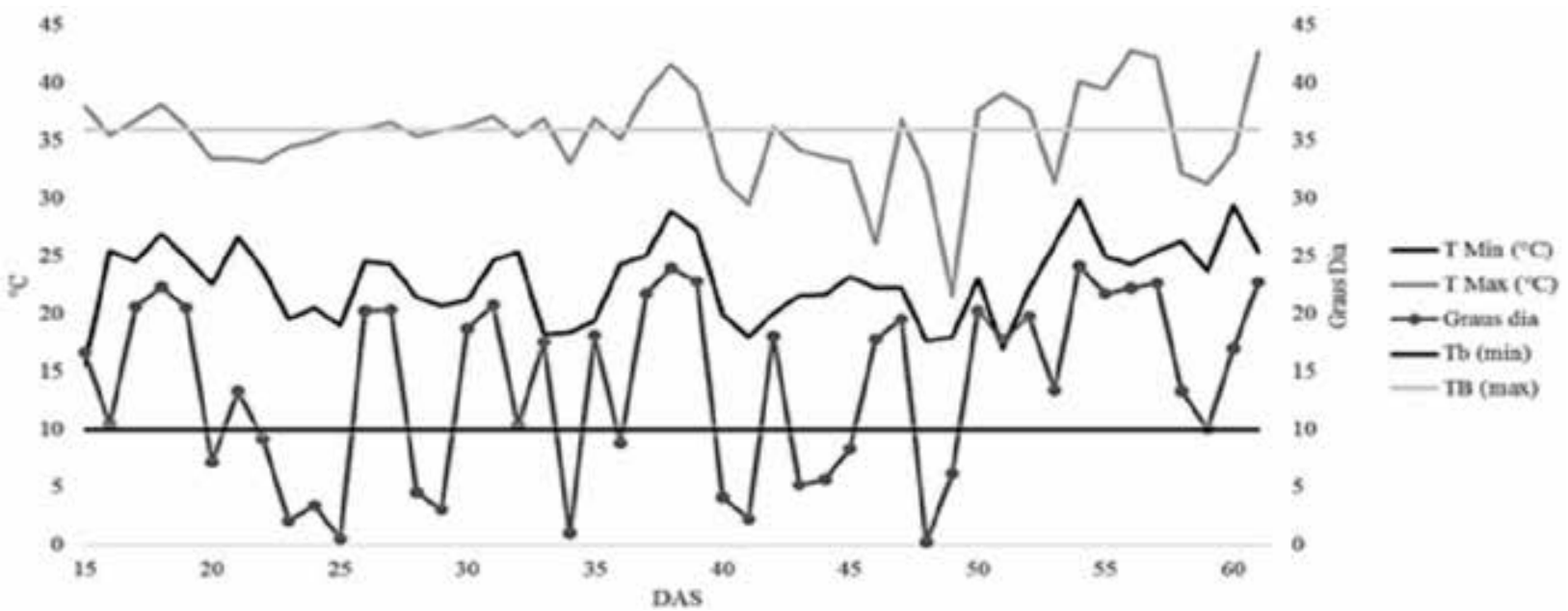

Figura 1. Acúmulo de graus-dia, temperatura base mínima de $10^{\circ} \mathrm{C}(\mathrm{Tb})$, temperatura base máxima de $36^{\circ} \mathrm{C}(\mathrm{TB})$, temperatura mínima e máximas, durante o desenvolvimento do maracujazeiro FB 200 e maracujazeiro-azedo na fase de viveiro, Jataí-GO, 2017
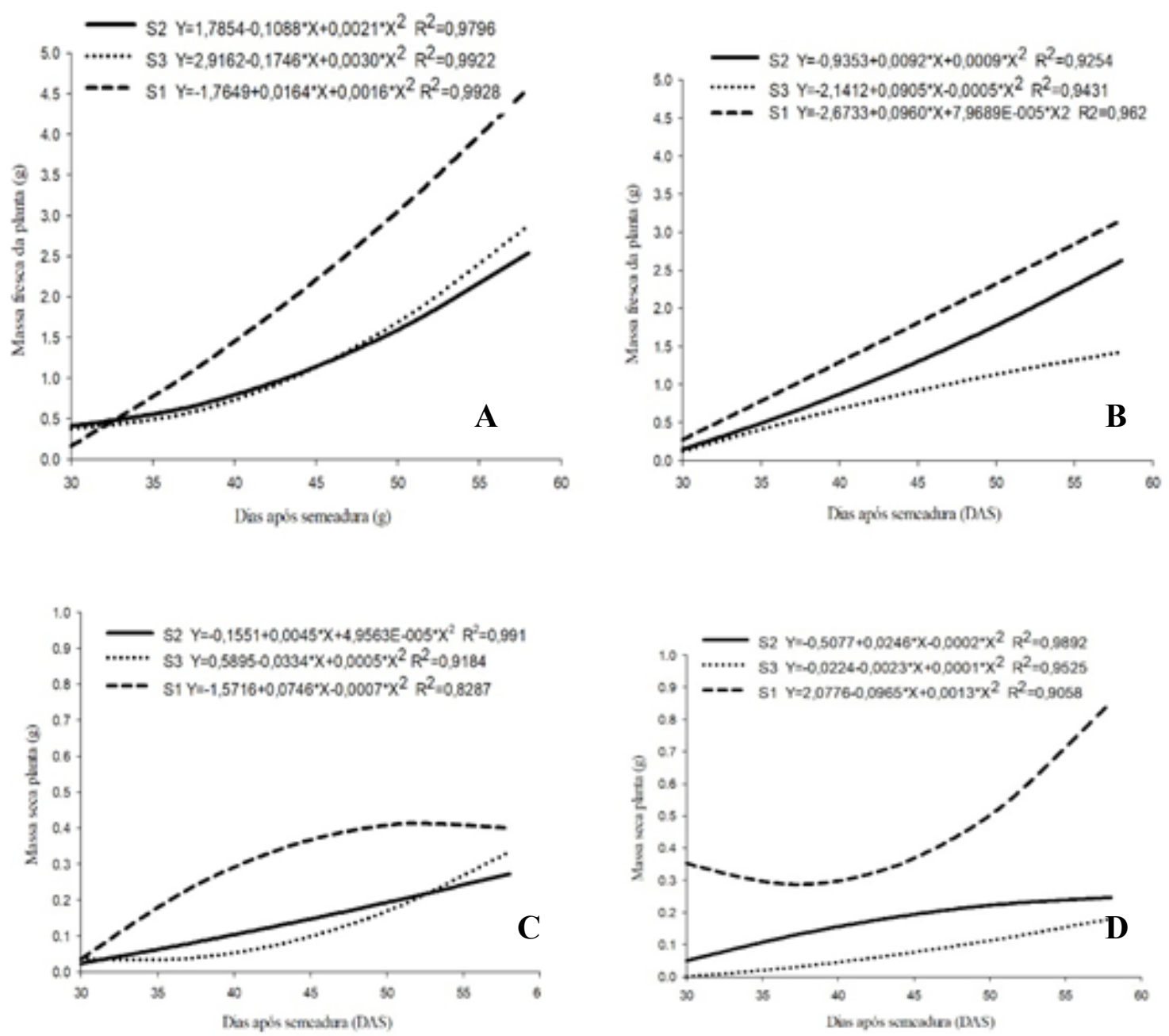

Figura 2. Dados ajustados para o teor de massa fresca da planta de maracujazeiro FB 200 (A), teor de massa fresca da planta maracujazeiro-azedo (B), teor de massa seca da planta de maracujazeiro FB 200 (C) e teor de massa seca da planta (g) maracujazeiro-azedo (D) em três tipos de substratos 


\section{PROPAGAÇÃO DO MARACUJAZEIRO EM DIFERENTES SUBSTRATOS}

é fundamental, pois possibilita saber a quantidade de nutrientes contida nas mudas, assim é possível afirmar que o substrato Bioplant ${ }^{\mathbb{B}}$, assim como o verificado pelos referidos autores, proporcionou maior quantidade de nutrientes nas mudas de FB 200 e maracujazeiro-azedo cultivadas no S1.

Para a variável MFPA, observou-se ajuste quadrático para as mudas da cultivar FB 200 e do maracujazeiro-azedo em resposta à variação no tempo (Figura 3A e 3B). Maior incremento inicial de MFPA foi verificado para mudas da cultivar FB 200 cultivadas no S1 aos 30 DAS, com média de $0,20 \mathrm{~g}$, e aos 58 DAS, 2,27 g. Para as mudas de maracujazeiro-azedo observou-se maior desempenho aos 30 DAS no S2, com média de 0,11 $\mathrm{g}$, sendo superado por S1 aos 58 DAS, com média de 2,57 g de MFPA. Os resultados observados para MFPA diferiram dos obtidos por Caproni et al. (2013), que, trabalhando com maracujazeiroamarelo em casa de vegetação e avaliando diferentes substratos, obtiveram resposta máxima de $1,21 \mathrm{~g}$ de MFPA, quando utilizado o substrato comercial Provaso $^{\circledR}+$ areia + terra de subsolo em 120 DAS. Esse resultado foi inferior ao observado quando utilizado o substrato Bioplant ${ }^{\circledR}$, o qual apresentou condições mais favoráveis para produção de mudas da cultivar FB 200 e do maracujazeiro-azedo do que os testados pelos referidos autores, demonstrando que o substrato inerte, mesmo em combinação, foi menos eficiente na formação de mudas do que o substrato comercial.

Tais resultados são relevantes, pois permitem saber o conteúdo de água presente nas mudas, as quais possuem maior tolerância em casos de dessecação e, em situação de transplantio, estarão mais aptas às condições de estresse ambiental.
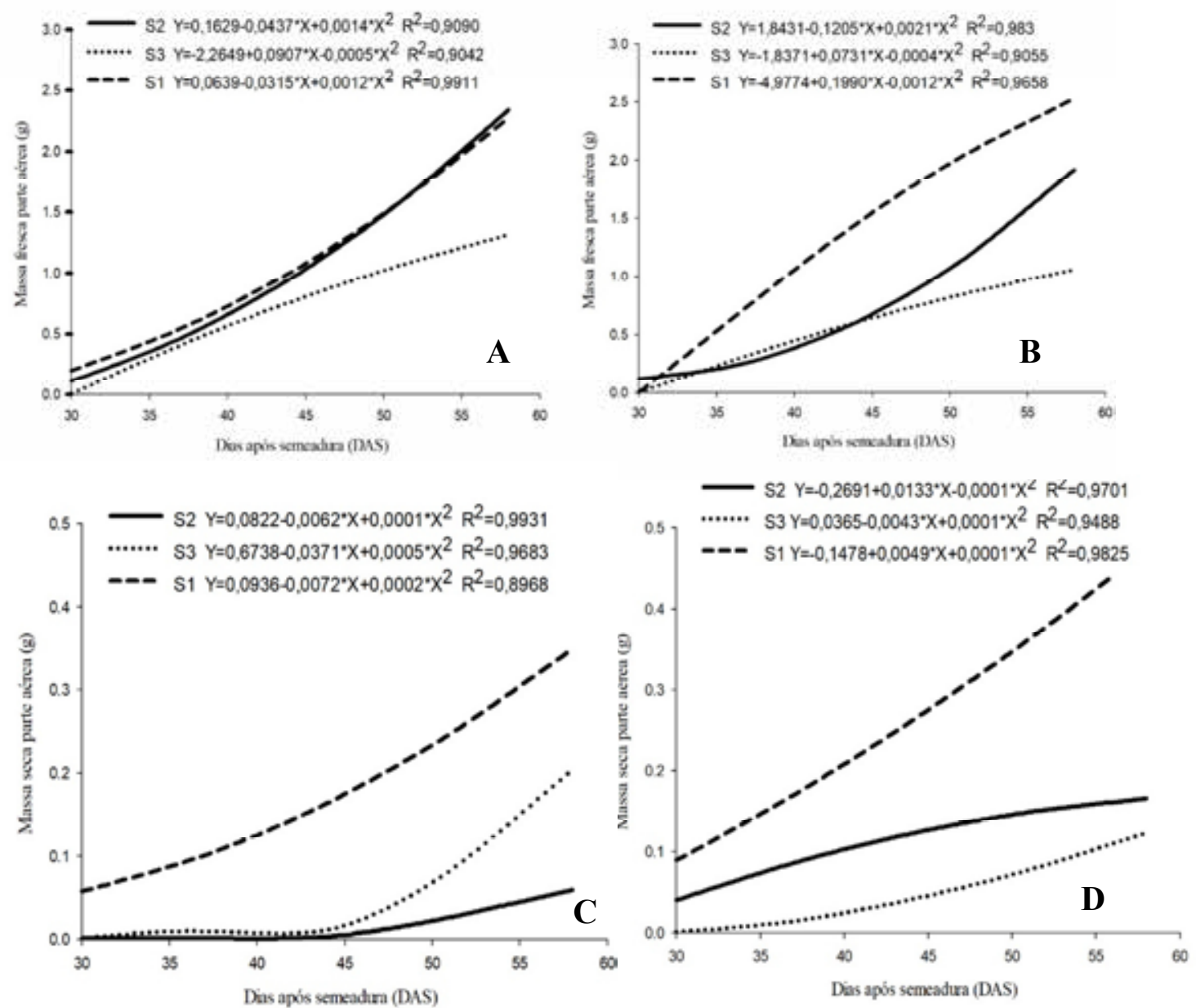

Figura 3. Dados ajustados para o teor de massa fresca da parte aérea (g) de maracujazeiro FB 200 (A), teor de massa fresca da parte aérea (g) maracujazeiro-azedo (B), teor de massa seca da parte aérea (g) de maracujazeiro FB 200 (C) e teor de massa seca da parte aérea (g) maracujazeiro-azedo (D) em três tipos de substratos 
A MSPA das mudas da cultivar FB 200 e do maracujazeiro-azedo cultivadas no substrato $\mathrm{S} 1$ apresentou melhor resposta quanto à variável MSPA, em que foram ajustadas pelo modelo quadrático em função da resposta à variação do tempo (Figura $3 \mathrm{C}$ e Figura 3D). Jeromini et al. (2018) constataram que o substrato comercial foi mais favorável para o desenvolvimento de mudas, onde promoveu maior incremento em MSPA nas plantas de Plukenetia volubilis $\mathrm{L}$, sendo observado o acúmulo médio de $0,55 \mathrm{~g}$ de MSPA. Esses resultados se devem às características do substrato, que forneceu a aeração, maior retenção de humidade e manutenção de temperatura ideal ao desenvolvimento das mudas, assim como verificado neste trabalho.

A MSPA é um parâmetro que indica a resistência das mudas, frente a vários fatores, como temperatura e presença de insetos. Dessa forma, foi possível verificar que as mudas da cultivar FB 200 e do maracujazeiro-azedo, quando cultivadas no S1, apresentaram maior acúmulo de MSPA, tendo resultado em melhor desempenho quando comparadas com o S2 e S3.

Para a variável MFR, houve ajuste quadrático para mudas da cultivar FB 200 e do maracujazeiroazedo cultivadas no S1 (Figura 4A e Figura 4B). As médias para mudas da cultivar FB 200 aos 30 DAS foi de $0,02 \mathrm{~g}$ e aos $58 \mathrm{DAS}, 0,14 \mathrm{~g}$ e as médias observadas para o maracujazeiro-azedo foram de $0,02 \mathrm{~g}$ aos 30DAS e 0,19 aos 58 DAS. Observouse um ajuste exponencial em ambos os tratamentos para mudas da cultivar FB 200 e maracujazeiroazedo em função do tempo de avaliação para MSR (Figura 4C e Figura 4D).
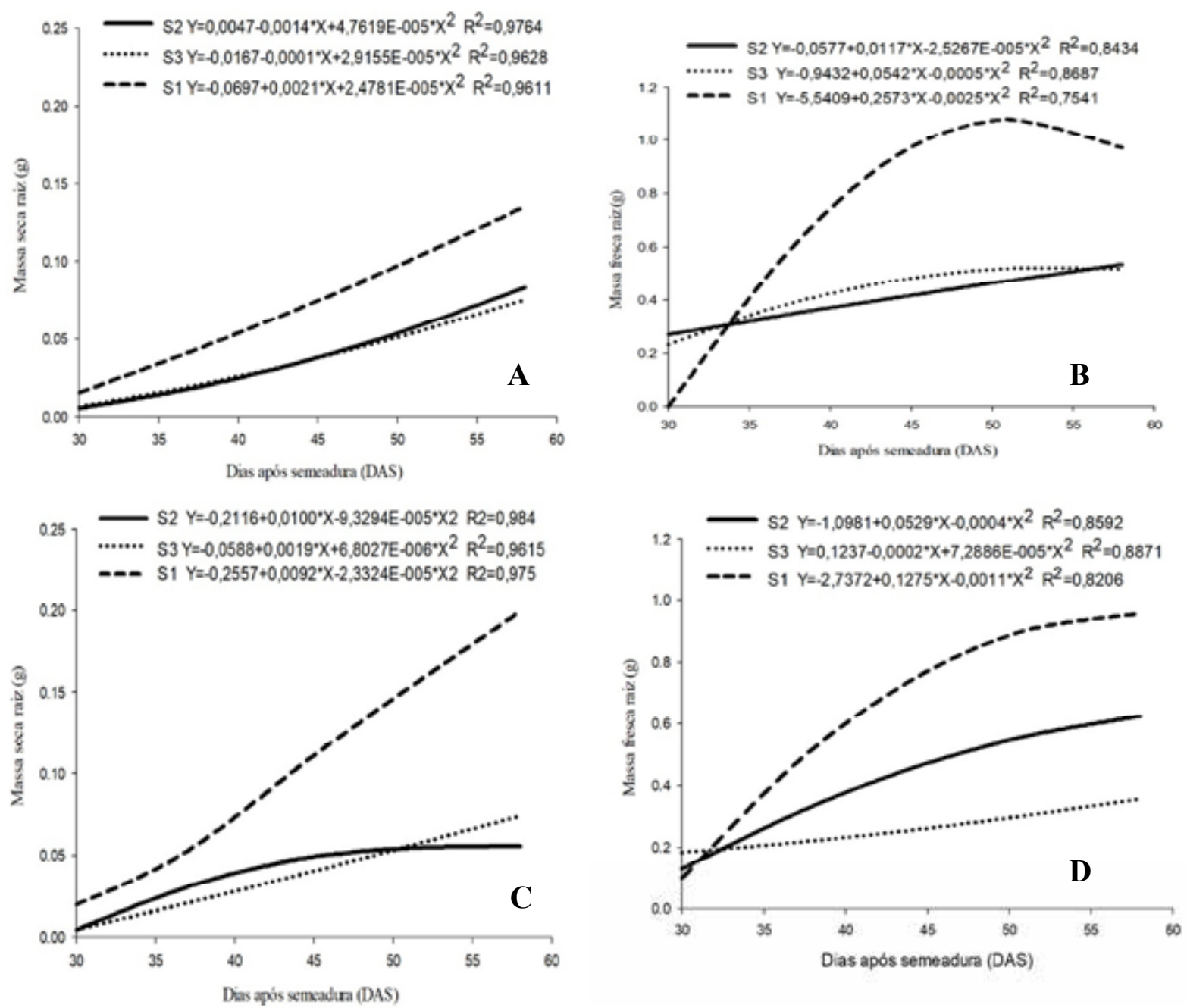

Figura 4. Dados ajustados para o teor de massa fresca da raiz (g) de maracujazeiro FB 200 (A), teor de massa fresca da raiz (g) maracujazeiro-azedo (B), teor de massa seca da raiz $(\mathrm{g})$ de maracujazeiro FB 200 (C) e teor de massa seca da raiz (g) maracujazeiro-azedo (D) em três tipos de substratos 


\section{PROPAGAÇÃO DO MARACUJAZEIRO EM DIFERENTES SUBSTRATOS}

A MSR é um dos parâmetros fundamentais na avaliação da qualidade das mudas. Com essa variável, pode ser feita a seleção dos melhores materiais a serem levados ao campo. Mudas com maior MSR contam com maior reserva temporária de assimilados, o que garante maior sobrevivência dessas mudas no campo (JEROMINI et al., 2018).

Ressalta-se ainda que aumento da MSR é um bom indicativo do desenvolvimento radicular e como consequência maior área a ser explorada é obtida. Maior massa radicular garante melhor exploração do solo tanto em volume como em profundidade, e tais características favorecem ainda a disponibilidade hídrica, que consequentemente é beneficiada pelo suprimento de minerais essenciais as plantas (MORGADO et al., 2017).

Castro et al. (2012), avaliando 10 substratos para a produção de mudas de maracujazeiro-amarelo em casa de vegetação, aos 70 DAS, obtiveram médias de 0,042 a $0,325 \mathrm{~g}$ de MFR e médias de 0,025 a $0,059 \mathrm{~g}$ de MSR, valores inferiores aos observados no presente trabalho.

Tais resultados de MFR e MSR comprovaram que a utilização do Bioplant ${ }^{\circledR}$ favoreceu $o$ desenvolvimento radicular, propiciando maior quantidade de água e nutrientes para as mudas, sendo a média de 0,047 a $0,475 \mathrm{~g}$ de MFR e médias de 0,0167 a $0,047 \mathrm{~g}$ de MSR.

Observou-se para o NF um ajuste quadrático para as mudas do cultivar FB 200 e do maracujazeiroazedo em resposta à variação do tempo (Figura $5 \mathrm{~A}$ e Figura 5B). As mudas do maracujazeiro-azedo cultivadas no $\mathrm{S} 1$ tiveram médias de 1,75 a 5,92 folhas dos 30 aos 58 DAS.
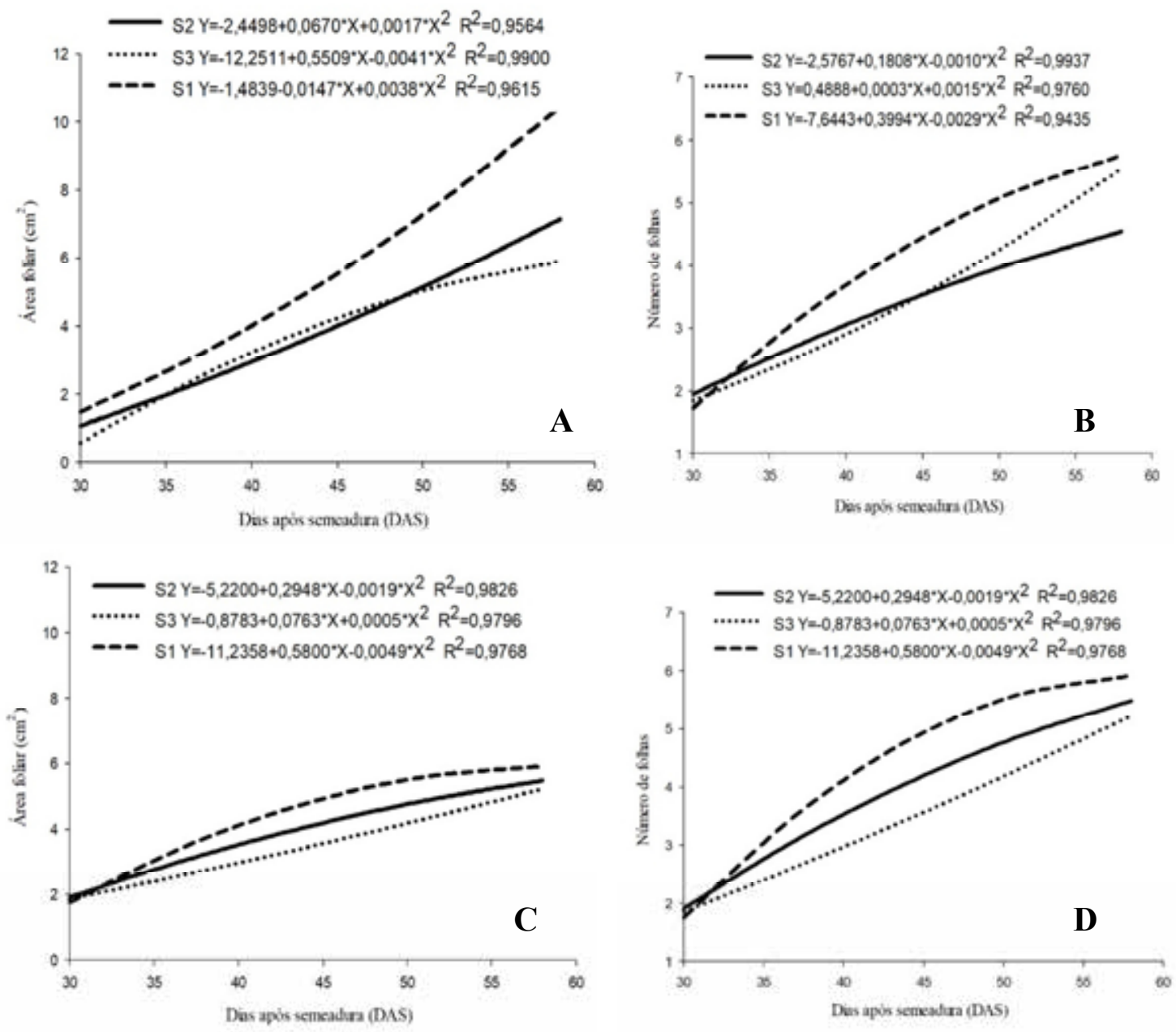

Figura 5. Dados ajustados para número de folhas de maracujazeiro FB 200 (A), e número de folhas de maracujazeiro-azedo (B), área foliar $\left(\mathrm{cm}^{2}\right)$ de maracujazeiro FB 200 (C) e área foliar $\left(\mathrm{cm}^{2}\right)$ de maracujazeiro-azedo (D) em três tipos de substratos 
Resultados semelhantes foram obtidos por Silva et al. (2016), que, avaliando tipos de recipientes e substratos na produção de mudas de maracujazeiro-amarelo, observaram médias de 3,85 a 5,0 folhas e concluíram que a utilização do substrato comercial promoveu maior crescimento do NF nas mudas de maracujazeiro-amarelo, corroborando com o presente trabalho. O NF é uma característica importante, pois é determinante para o estabelecimento das mudas devido à capacidade fotossintética destas (BOECHAT et al., 2010).

A AF das mudas da cultivar FB 200 e do maracujazeiro-azedo apresentou excelente desempenho quando cultivadas no $\mathrm{S} 1$, com médias de 1,05 a $8,17 \mathrm{~cm}^{2}$ dos 30 aos 58 DAS, procedendo para tais dados o ajuste quadrático, conforme resposta à variação do tempo (Figura 5C e Figura 5D).
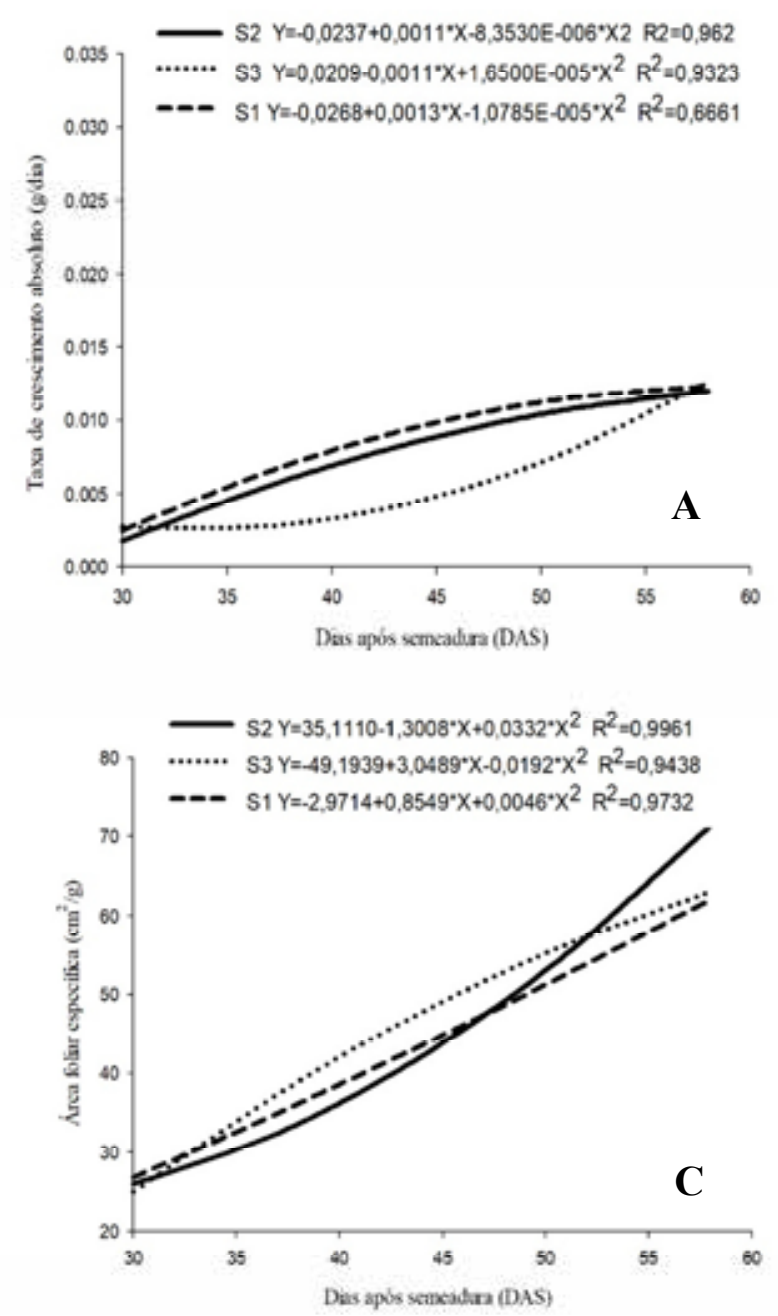

Segundo Morgado et al. (2013), a folha é um o órgão de grande importância em todo processo transpiratório, e, nas trocas gasosas que ocorrem entre planta e ambiente, compreender todos os fatores relativos a esse parâmetro é fundamental, pois permite inferir sobre o crescimento e o desenvolvimento das plantas.

A AFE das mudas da cultivar FB 200 cultivadas no S1 teve melhor desenvolvimento até os 51 DAS, sendo superadas por S2 aos 51 DAS. As médias para o $\mathrm{S} 2$ variaram de 25,96 a $71,34 \mathrm{~cm}^{2} / \mathrm{g}$, já a AFE das mudas do maracujazeiro-azedo cultivadas no $\mathrm{S} 3$ apresentou aumento crescente. As médias observadas dos 30 aos 58 DAS para mudas cultivadas no $\mathrm{S} 3$ foram de 39,97 a $172,11 \mathrm{~cm}^{2} / \mathrm{g}$ (Figura 6A e Figura 6B).

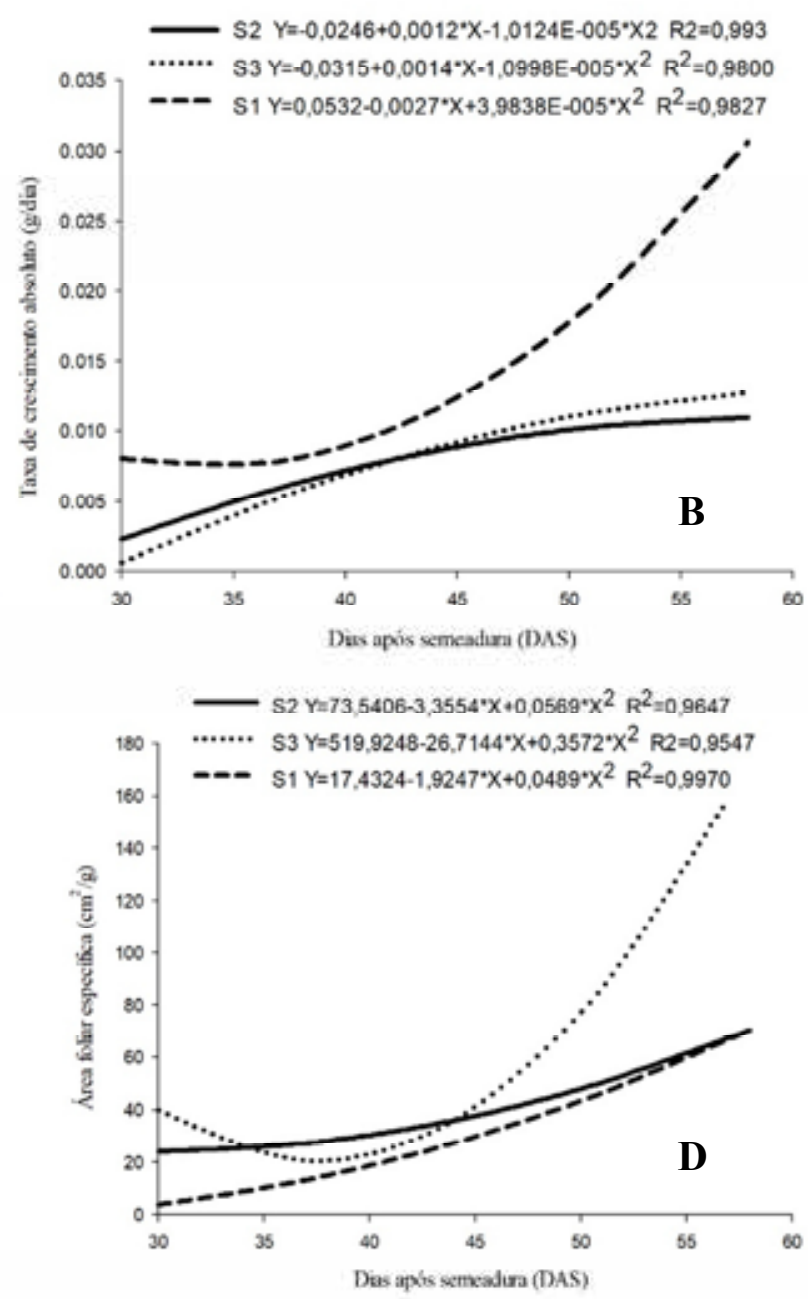

Figura 6. Dados ajustados para área foliar específica $\left(\mathrm{cm}^{2} / \mathrm{g}\right)$ de maracujazeiro FB 200 (A), e área foliar específica $\left(\mathrm{cm}^{2} / \mathrm{g}\right)$ de maracujazeiro-azedo (B), taxa de crescimento absoluto (g/dia) de maracujazeiro-azedo (C) e taxa de crescimento absoluto (g/dia) do cultivar FB 200 (D) em três tipos de substratos 


\section{PROPAGAÇÃO DO MARACUJAZEIRO EM DIFERENTES SUBSTRATOS}

De acordo com Bezerra et al. (2016), a AFE indica a espessura das folhas, a qual tem relação direta de sua superfície com a massa seca foliar. $\mathrm{O}$ aumento desse parâmetro é comum em locais de baixas condições de luz. De acordo com Valle et al. (2018b), quando ocorre a redução da AFE, as plantas, sob condições de alta insolação, são beneficiadas, pois ocorre a redução de perda de água e o autossombreamento, devido à menor exposição dos tecidos ao sol, o que foi observado para a cultivar FB 200 cultivada no S1 e para o maracujazeiro-azedo cultivado no $\mathrm{S} 3$.

A TCA para mudas da cultivar FB 200 e mudas de maracujazeiro-azedo foi ajustada por meio de modelo exponencial (Figura 6C e Figura D). A TCA apresentou média de $0,012 \mathrm{~g}$ /dia para $\mathrm{S} 1$ para FB 200 e para o maracujazeiro-azedo médias de 0,081 a $0,031 \mathrm{~g} /$ dia aos 58 DAS.

Esses resultados divergem dos verificado por Santos et al. (2017), que, em produção de mudas do maracujazeiro-amarelo com diferentes materiais refletores sobre bancadas, observaram para essa variável as médias de 0,18 a $0,20 \mathrm{~g} /$ dia dos 30 aos 70 DAS. De acordo com os autores, o acúmulo de TCA serve como um indicativo de qualidade e demonstra o incremento em biomassa seca na planta, colaborando com o entendimento de que maior TCA foi acumulada nas mudas da cultivar FB 200 e maracujazeiro-azedo cultivadas no S1 se destacaram quanto a essa característica.

Com base na avaliação do $\mathrm{DC}$, verificou-se aos 30 DAS que não houve diferença estatística quanto aos substratos testados para as mudas do cultivar FB 200, diferindo apenas das mudas do maracujazeiro-azedo conduzidas nos diferentes substratos. As médias para a cultivar FB 200 variaram de 1,71 a $1,81 \mathrm{~mm}$ (Tabela 1 ).

Aos 37 DAS, somente as mudas da cultivar FB 200 conduzidas no S2, diferiu estatisticamente dos demais tratamentos. Essa diferença pode ser atribuída ao menor incremento das mudas cultivadas no S2, no período avaliado, que, de acordo Lima et al. (2016), em estudo com diferentes substratos e ambientes protegidos para o crescimento de mudas de maracujazeiro-amarelo, os substratos que continham pequenas proporções de Bioplant ${ }^{\mathbb{B}}$ apresentaram as menores plantas com os menores diâmetros, o que pode estar relacionado às características físicas e químicas do substrato utilizado.

Tabela 1. Diâmetro do caule e teor de clorofila total (ICF) de maracujazeiro FB 200, e maracujazeiro-azedo na fase de viveiro, Jataí-GO, 2016

\begin{tabular}{lcccc}
\hline \multirow{2}{*}{ Espécie } & \multicolumn{4}{c}{ Diâmetro do caule } \\
\cline { 2 - 5 } & 30 DAS & 37 DAS & 44 DAS & 51 DAS \\
\hline FB200 S2 & $1,71 \mathrm{a}^{*}$ & $2,02 \mathrm{~b}$ & $2,63 \mathrm{a}$ & $2,65 \mathrm{a}$ \\
FB200 S3 & $1,72 \mathrm{a}$ & $2,61 \mathrm{a}$ & $2,69 \mathrm{a}$ & $2,74 \mathrm{a}$ \\
FB200 S1 & $1,81 \mathrm{a}$ & $2,41 \mathrm{ab}$ & $2,76 \mathrm{a}$ & $2,65 \mathrm{a}$ \\
M-Azedo S2 & $1,38 \mathrm{~b}$ & $2,57 \mathrm{a}$ & $2,74 \mathrm{a}$ & $2,75 \mathrm{a}$ \\
M-Azedo S3 & $1,19 \mathrm{~b}$ & $2,69 \mathrm{a}$ & $2,67 \mathrm{a}$ & $2,74 \mathrm{a}$ \\
M-Azedo S1 & $1,21 \mathrm{~b}$ & $2,64 \mathrm{a}$ & $2,70 \mathrm{a}$ & $2,53 \mathrm{a}$ \\
\hline CV (\%) & 19,57 & 11,45 & 3,45 & 5,86 \\
\hline & & Teor de clorofila total & \\
\hline FB200 S2 & $50,00 \mathrm{~b}$ & $38,03 \mathrm{a}$ & $40,70 \mathrm{bc}$ & $39,70 \mathrm{a}$ \\
FB200 S3 & $49,90 \mathrm{~b}$ & $40,63 \mathrm{a}$ & $46,97 \mathrm{a}$ & $45,20 \mathrm{a}$ \\
FB200 S1 & $50,33 \mathrm{~b}$ & $49,10 \mathrm{a}$ & $39,20 \mathrm{c}$ & $35,17 \mathrm{a}$ \\
M-Azedo S2 & $52,50 \mathrm{a}$ & $29,61 \mathrm{a}$ & $48,07 \mathrm{a}$ & $39,70 \mathrm{a}$ \\
M-Azedo S3 & $53,20 \mathrm{a}$ & $45,83 \mathrm{a}$ & $48,60 \mathrm{a}$ & $36,20 \mathrm{a}$ \\
M-Azedo S1 & $54,00 \mathrm{a}$ & $35,47 \mathrm{a}$ & $44,50 \mathrm{ab}$ & $41,23 \mathrm{a}$ \\
\hline CV (\%) & 20,34 & 18,23 & 9,93 & 15,81 \\
\hline
\end{tabular}

*Médias seguidas pela mesma letra não são diferem entre si em nível ao nível de $5 \%$ probabilidade pelo teste Tukey. 
Aos 44 e 51 DAS, os tratamentos não diferiram estatisticamente entre si para as mudas de FB 200 e maracujazeiro-azedo. O Bioplant ${ }^{\circledR}$ se destacou dos demais possivelmente por conter casca de pinus, esterco, vermiculita e outros componentes. Segundo Moreira et al. (2015), os substratos comerciais podem fazer as plântulas emergirem mais rapidamente, o que não onera nos custos finais de produção.

O TCT aos 30 DAS foi superior para as mudas de maracujazeiro-azedo, nos três substratos utilizados, diferindo estatisticamente das mudas do cultivar FB 200 nos seus respectivos substratos, as médias variaram de 52,50 a 54,00. Aos 37 DAS, não foram verificadas diferenças estatísticas entre as mudas do cultivar FB 200 e maracujazeiroazedo e os substratos. Os teores de clorofila possuem correlação direta com a concentração de $\mathrm{N}$ nas plantas, podendo ser estimadores do potencial fotossintético, colaborando na avaliação da qualidade das mudas, sendo que quanto maior for o valor de TCT, melhor será a produtividade das plantas (KLOOSTER et al., 2012; MIYAKE et al., 2017).

Aos 51 DAS, as mudas do maracujazeiroazedo e da cultivar FB 200 não apresentaram diferença estatística em relação aos substratos utilizados. O TCT variou de 35,17 a 45,20. Tais resultados denotaram a elevada capacidade de desenvolvimento das mudas de FB 200 e maracujazeiro-azedo quando cultivadas no S1.

\section{CONCLUSÃO}

- Os substratos promoveram o desenvolvimento das mudas da cultivar FB 200 e maracujazeiroazedo, sendo que $\mathrm{S} 1$ proporcionou os melhores resultados para maioria dos parâmetros avaliados, tais como massa fresca e seca da parte aérea e da raiz, influenciando diretamente na produção de mudas, sendo indicado seu uso na propagação do maracujazeiro.

\section{REFERÊNCIAS BIBLIOGRÁFICAS}

BEZERRA, J.D.; PEREIRA, W.E.; SILVA, J.M.; RAPOSO, R.W.C. Crescimento de dois genótipos de maracujazeiro-amarelo sob condições de salinidade. Ceres, Viçosa, v.63, n.4, p.88-96, 2016.

BOECHAT, C.L.; TEIXEIRA, A.M.; DA COSTA, A.S.V.; DE SOUZA BARBOSA, A.P. Influência de substratos associados à adubação mineral sobre o crescimento inicial de duas cultivares de maracujazeiro-amarelo. Revista Caatinga, Mossoró, v.23, n.3, p.19-25, 2010.

CAPRONI, C.M.; RAMOS, D.J.; NETO, J.V.; DE OLIVEIRA DA SILVA, L.F.; SIMÕES, J.C.; PEREIRA, W.R. Substratos e adubação nitrogenada na produção de mudas de maracujazeiro amarelo. Scientia Agraria, Curitiba, v.14, n.2, p.125-131, 2013.

CASIERRA-POSADA, F.; PEÑA, G.R.; PEÑAOLMOS, J.E. Estimación indirecta del área foliar en Fragaria vesca L., Physalis peruviana L., Acca sellowiana (Berg.) Burret, Rubus glaucus L., Passiflora mollissima (Kunth) L. H. Bailey y Ficus carica L. Revista U.D.C.A. Actualidad \& Divulgación Científica, Colômbia v.11, n.1, p.95102, 2007.

CASTRO, L.H.S.; ASSIS, R.T.; NOCITI, L.A.S.; ASSIS, J.C.; SILVA, L.G. Formação de mudas de maracujazeiro-amarelo com resíduo agroindustrial do processamento de batata como substrato. Revista Brasileira de Agrociência, Pelotas, v.18, n.2, p.102-111, 2012.

DAMATTO-JUNIOR, E.R.; FUZITANI, E.J.; NOMURA, E.S. Produção de maracujá com uso de mudas avançadas no Vale do Ribeira. Pesquisa \& Tecnologia, São Paulo, v.11, n.1, p.1123-1131, 2014.

FALKER, Automação agrícola. Manual do medidor eletrônico de teor clorofila (ClorofiLOG/ CFL 1030). Porto Alegre, 2008. 33p. Disponível em: <http://www.falker.com.br/produtodownload. php?id=4>. Acesso em: 06 Mai. 2018.

GOMES, F.P. Curso de Estatística Experimental ed. 14. Piracicaba: USP/ESALQ, 2000. 477p.

GONÇALVES, E.O.; PETRI, G.M.; CALDEIRA, M.V.W.; DALMASO, T.T.; SILVA, A.G. 
Crescimento de mudas de Ateleia glazioviana em substratos contendo diferentes materiais orgânicos. Revista Floresta e Ambiente, Seropédica v.21, n.3, p.339-348, 2014.

GONDIN, J.C.; SILVA, J.B.; ALVES, C.Z.; DUTRA, A.S.; JUNIOR, L.E. Emergência de plântulas de Schizolobium amazonicum Huber ex Ducke (CAESALPINACEAE) em diferentes substratos e sombreamento. Revista Ciência Agronômica, Ceará v. 46, n.2, p.329-338, 2015.

IBGE. Anuário Estatístico do Brasil. Sistema IBGE de recuperação automática. Rio de Janeiro: IBGE/ SIDRA. Disponível em: < http://www.sidra. ibge.gov.br> (Acesso em 14 Mai. 2018).

JEROMINI, T.S.; BARBOSA, A.S.; DA SILVA, G.Z.; MARTINS, C.C. Substrate and seed sowing position on the production of Plukenetia volubilis L. seedlings. Revista Brasileira de Engenharia Agrícola e Ambiental-Agriambi, Campina Grande. 22, n.6, p.49-56, 2018.

KLOOSTER, W.S.; CREGG, B.M.; FERNANDEZ, R.T.; NZOKOU, P. Growth and physiology of deciduous shade trees in response to controlled release fertilizer. Scientia Horticulturae, Amsterdam, v.35, p.71-79, 2012.

LIMA, I.M.O.; SILVA JÚNIOR, J.S.; COSTA, E.; CARDOSO, E.D.; BINOTTI, F.F.S.; JORGE, M.H.A. Diferentes substratos e ambientes protegidos para o crescimento de mudas de maracujazeiro amarelo. Revista de Agricultura Neotropical, Cassilândia, v.3, n.4, p.39-47, 2016.

MARINHO, P.H.A.; SOUSA, R.M.; GIONGO, M.; VIOLA, M.R.; SOUZA, P.B. Influência de diferentes substratos na produção de mudas de flamboyant Delonix regia (Bojer ex Hook.) Raf. Revista Agro@mbiente On-line, Boa Vista, v.11, n.1, p.40-46, 2017.

MIYAKE, R.T.M.; CRESTE, J.E.; NARITA, N.; GUERRA, W.E.X. Substrato e adubação nitrogenada na produção de mudas de maracujazeiro amarelo em condições protegidas. Colloquium
Agrariae, Presidente Prudente, v.13, p.57-65, 2017.

MOREIRA, C.V.; JOÃO, C.L.; CASSANJE, S.B.; CANDA, D.M; SILVA, S.O. Propagação do maracujazeiro amarelo em recipiente de poliestireno sob diferentes substratos. Magistra, Cruz das Almas, v.27, n.1, p.63-72, 2015.

MORGADO, M.A.D.; BRUCKNER, C.H.; ROSADO, L.D.S.; ASSUNÇÃO, W.; SANTOS, C.E.M. Estimação da área foliar por método não destrutivo, utilizando medidas lineares das folhas de espécies de Passiflora. Revista Ceres, Viçosa, v.60, n.5, p.662-667, 2013.

MORGADO, M.A.D.O.; BRUCKNER, C.H.; ROSADO, L.D.S.; DOS SANTOS, C.E.M. Growth dynamics and allometric relationships of Passiflora species rootstocks. Comunicata Scientiae, Viçosa, v.8, n.1, p.1-8, 2017.

NAKAGAWA, J. Testes de vigor baseados na avaliação das plântulas. In: VIEIRA, R.D.; CARVALHO, N.M. Testes de vigor em sementes. Jaboticabal: Funep, 1999. p.49-85.

NOGUEIRA, A.C.; SOUZA, P.G.; KRATZ, D.; BASSACO, M.V.M. Adição de maravalha a substratos comerciais na produção de mudas de Eucalyptus grandis Hill ex Maiden Adding wood shavings to commercial substrates in the production of seedlings of Eucalyptus grandis Hill ex Maiden. Ambiência, Guarapuava, v.10, n.2, p.527-538, 2014.

REIS, J.M.R.; RODRIGUES, J.F.; REIS, M. Produção de mudas de maracujazeiro amarelo com diferentes substratos. Enciclopédia Biosfera, Goiânia v.10, n.18, p.2422-2428, 2014.

RENATO, N.S.; SILVA, J.B.L.; SEDIYAMA, G.C.; PEREIRA, E.G. Influência dos métodos para cálculo de graus-dia em condições de aumento de temperatura para as culturas de milho e feijão. Revista Brasileira de Meteorologia, São Paulo, v.28, n.4, p.122-129, 2013. 
SALAZAR, A.H.; SILVA, D.F.P.; PICOLI, E.T.; BRUCKNER, C.H. Desenvolvimento, florescimento e análise morfoanatômica do maracujazeiro-amarelo enxertado em espécies silvestres do gênero passiflora. Revista Brasileira de Ciências Agrárias, Recife, v.11, n.4, p.323329, 2016.

SANTOS, T.V.; LOPES, T.C.; SILVA, A.G.; PAULA, R.D.C.M.; COSTA, E.; SILVA BINOTTI, F.F. Produção de mudas de maracujá amarelo com diferentes materiais refletores sobre bancada. Revista de Agricultura Neotropical, Cassilândia, v.4, n.4, p.26-32, 2017.

SAS INSTITUTE. SAS: User's guide: statistics. Version 8.2. Cary: SAS Institute Inc., 2002.

SILVA SÁ, F.V.; BERTINO, A.M.P.; FERREIRA, N.M.; BERTINO, A.M.P.; DA SILVA SOARES, L.; DE MESQUITA, E.F. Formação de mudas de maracujazeiro amarelo com diferentes doses de esterco caprino e volumes do substrato. Magistra, Cruz das Almas, v.26, n.4, p.482-492, 2017.

SILVA, R.P.D.; PEIXOTO, J.R.; JUNQUEIRA,
N.T.V. Influência de diversos substratos no desenvolvimento de mudas de maracujazeiro azedo (Passiflora edulis Sims f. flavicarpa DEG). Revista Brasileira de Fruticultura, Jaboticabal, v.23, n.2, p.377-381, 2001.

SILVA, W.L.; BRITO, A.S.; BRITO, C.F.B.; MESQUITA, N.L.S.; SILVA, Y.C.P. Passion fruit development in containers and substrates the vermiculite waste base. Revista Agrotecnologia, Ipameri, v.7, n.2, p.53-60, 2016.

VALLE, K.D.; PEREIRA, L.D.; BARBOSA, M.A.; CHAVES, V.B.S.; SOUZA, P.H.M.; REIS, E.F.; SALAZAR, A.H.; SILVA, D.F.P. Development and root morphology of passion fruit in different substrates. Revista Colombiana de Ciências Hortícolas, Colômbia, v.12, n.2, p.514520, 2018a.

VALLE, K.D.; CHAVES, V.B.S.; PEREIRA, L.D.; REIS, E.F.; SALAZAR, A.H.; SILVA, D.F.P. Chlorophyll content and degrees day accumulation in passion fruit species in the Southwest of Goiás, Brazil. Comunicata Scientiae, Bom Jesus, v.9, n.3, p.351-355, 2018b. 